\title{
DESIGN AND ANALYSIS OF DATA CLASSIFICATION WITH CONTROL OF SAFETY SCHEMES
}

\author{
Dr. Nirmla Sharma \\ Asst. Professor, Computer Science, \\ KKU University Abha, Saudi Arabia
}

\begin{abstract}
Effective and efficient safety of control system statistics, in terms of both operational difficulty and cost, involves that the types of data used in the system be recognized and classified according to their importance in operating the control system safety.

Lastly, the practical execution particulars has defined that will run the level of safety stated by the security profile. The method it has presented in this research paper considers both the criticality of the statistics to the usual processes of the control system and exclusive features of a control system. The goal is a description of a practice for emerging an efficient, effective safety scheme for process control statistics. Our aim is to certify suitable levels of data safety while minimizing influence on the control system processes.
\end{abstract}

Keywords - Control System, Data Classification, Data warehousing, and Statistics

\section{INTRODUCTION (DATA ClASSIFICATION)}

It is the process of organizing data by agreed-on categories. Thoroughly planned classification enables more efficient use and protection of critical data across the organization and contributes to risk management, legal discovery and compliance processes. Following two methods have recycled to organize statistics:

- Statistics has categorized permitting to its feeling. Highly-sensitive data is categorized by way of extremely controlled and less-sensitive data is considered as per fewer limiting [1].

- Statistics may also be categorized permitting to work purpose. This control permits only detailed consumers to opinion individual statistic. Now it limits consumers to observation person that share of figures in which it has complicated and are accountable for.

There are roughly problems in another method. To recognize, let's need an instance. Assume it has structure data warehouse used for series. Consider that statistics actuality kept in data warehouse is operation statistics for altogether versions. Request now, who has permitted to realize contract statistics, explanation lies in categorizing statistics permitting to purpose [2].

\subsection{Consumer classification}

Following methods have recycled to categorize consumers:

- $\quad$ Consumers have categorized by way of order clients in society, i.e., it may be characterized by units, segments, collections, and so on.

- Consumers may also be considered permitting to their part, with society collected crossways sectors created on their part.

\subsection{Classification on source of Subdivision}

In this example have shown data warehouse anywhere consumers are after deals and presentation section. It may have safety through top-to-down enterprise assessment, by contact run on dissimilar sections. But here would be around limitations on clients at dissimilar stages [3]. This organization has unprotected in following figure1.

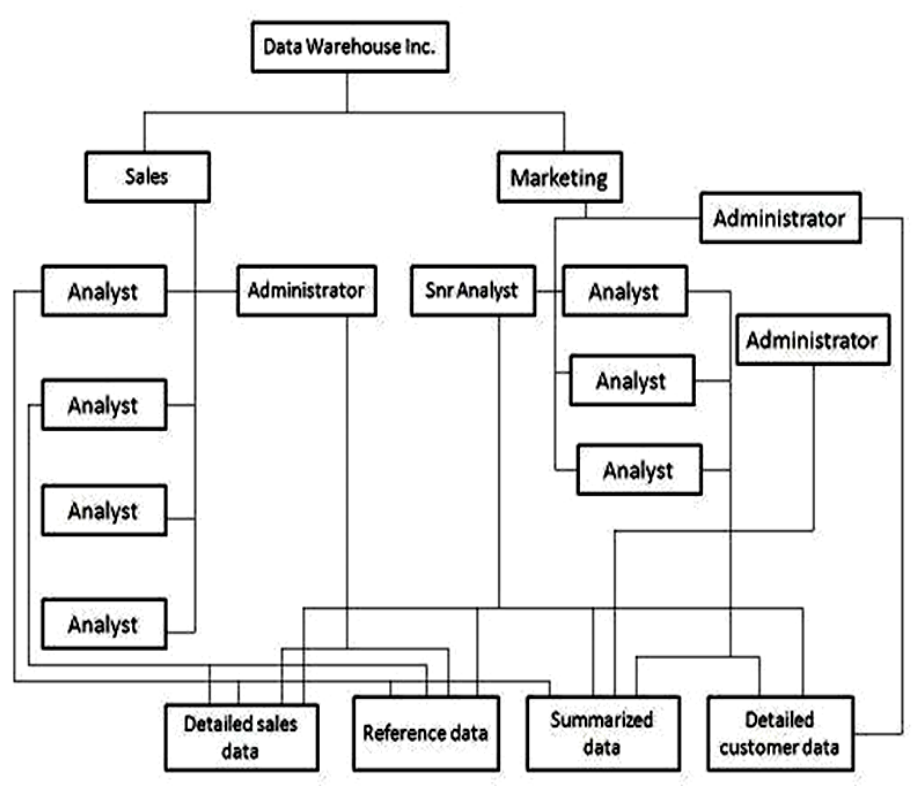

Fig1. Data warehouse classification on source of Subdivision [3] 


\section{International Journal of Engineering Applied Sciences and Technology, 2020 \\ Vol. 4, Issue 10, ISSN No. 2455-2143, Pages 343-347 \\ Published Online February 2020 in IJEAST (http://www.ijeast.com)}

If each subdivision contacts dissimilar statistics, it should scheme safety control for individually section distinctly. This may be realized through departmental data marts. Meanwhile these data marts are disconnected from the data warehouse; it may impose distinct safety limitations on individually data mart [3]. This method is exposed in under figure2.

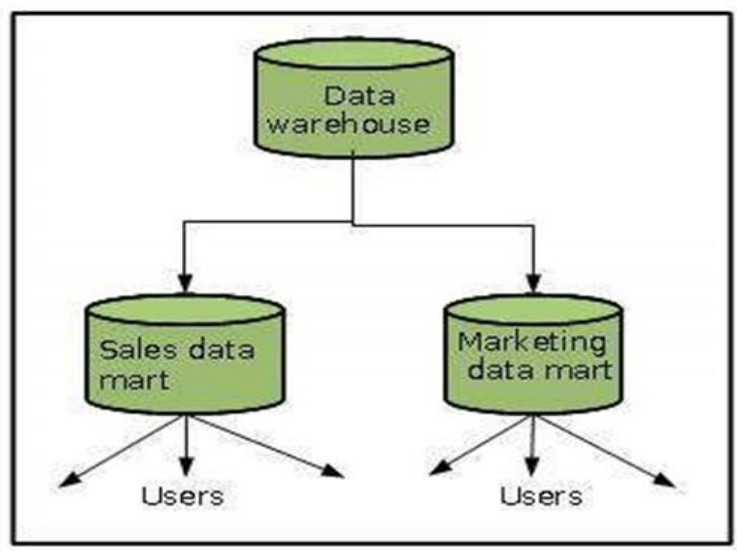

Fig2. Data warehouse subdivision exposed in data mart [4]

\section{PROBLEM STATEMENT}

There is no one-size-fits-all approach to data classification. However, the classification process can be broken down into four key steps, which you can tailor to meet your organization's unique needs as you develop your data protection strategy. Establish a data classification policy. First, you should define a data classification policy and communicate it to all employees who work with sensitive data. The reasons data classification has been put into place and the goals the company expects to achieve from it.

It defines sensitive data. Once the policy has established, it's time to decide whether you need data discovery. If you choose to classify only new data, some business-critical or sensitive data that you already have might be left insufficiently protected [5]. If that risk is unacceptable, you need to invest money, time and effort to run data discovery and apply your classification policies to your existing data.

\section{CLASSIFICATION ON SOURCE OF PART}

If statistics is usually obtainable to altogether sections, then it is valuable to follow part contact hierarchy. In other arguments, if statistics has usually retrieved by entirely show in this figure 3 .

\subsection{Audit Desires}

Auditing has subsection of safety and expensive action. It may foundation full expenses on system. To comprehensive an audit in period, it needs more hardware and so, it has optional that anywhere probable, reviewing would be exchanged off [6]. Audit desires may be considered as follows:

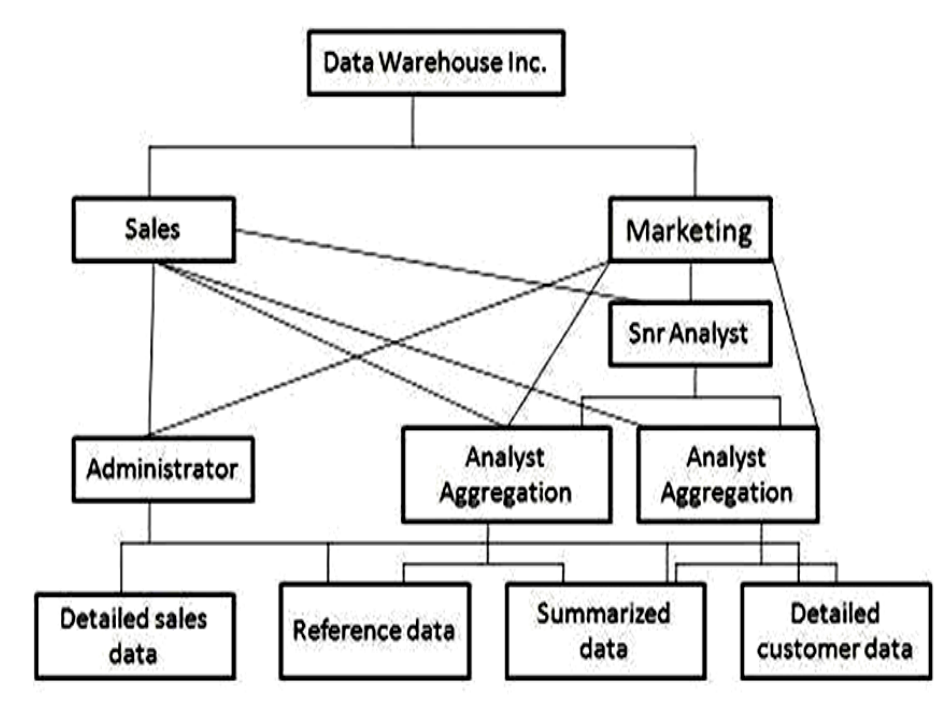

Fig3. Data warehouse classification on source of Part

- To associates

- To discontinuation

- To statistics contact

- To statistics change

Used for individually of above-mentioned groups, it has required reviewing achievement, disappointment, or equally. After viewpoint of safety details, revising of discontents are real vital. Reviewing of disappointment is significant since it may focus unapproved or fake contact [7].

\subsection{Network Desires}

Network safety has significant other safeties. It cannot overlook system safety need. It desires to show following concerns:

- Is it essential to encode statistics earlier transmitting it to data warehouse?

- Are their limitations on which network ways statistics may take?

These are limitations need to be measured carefully. Following are opinions to recollect:

- Procedure of encryption and decryption would growth expenses. It would need other treating control and treating period.

- Price of encryption may be great if scheme is now loaded system since encryption has allowed by basis structure.

\subsection{Statistics Association}




\section{International Journal of Engineering Applied Sciences and Technology, 2020 \\ Vol. 4, Issue 10, ISSN No. 2455-2143, Pages 343-347 \\ Published Online February 2020 in IJEAST (http://www.ijeast.com)}

There happen possible safety suggestions though affecting statistics. Assume it desires to assignment about controlled statistics by way of level file to be loaded. Once statistics is loaded into data warehouse, following requests are raised:

- Where is level organizer kept?

- Who has contact to that disk space?

If discussions about backup of these level files, following requests are raised:

- Does it backup encrypted or decrypted types?

- Do these backups essential to be complete to distinct tapes that are kept distinctly?

- Who has contact to these tapes?

Approximately more rules of statistics association similar request outcome collections also essential to be measured. Requests elevated though producing passing table are as follows:

- Where is that temporary table to be detained?

- How do you create such table observable?

It would avoid accidental breaking of safety limitations. If consumer with contact to limited statistics may make available impermanent tables, statistics may be observable to nonauthorized consumers. It may overcome this difficult by needing distinct passing part for consumers with contact to limited statistics [8].

\subsection{Certification}

Audit and safety desires need to be correctly recognized. This will be preserved as share of explanation [9]. This certificate may cover all statistics collected from:

- Statistics classification

- Consumer classification

- $\quad$ Network desires

- Statistics association and storage desires

- $\quad$ All suitable activities

\section{CONTROL OF SAFETy ON SCHEME}

Safety moves request cipher and growth periods. Control Safety moves to show below schemes-

- $\quad$ Request growth

- $\quad$ Record scheme

- Testing

\subsection{Request Growth}

Safety moves complete request growth and it also moves scheme of vital modules of data warehouse like load administrator, warehouse administrator, and query supervisor. Load administrator might need trying cipher to filter record and place them in dissimilar situations. Additional change instructions might also be essential to hide assured statistics. Similarly there might be desires of more metadata to switch any other articles.

To make and uphold more observations, warehouse administrator might involve more ciphers to impose safety. Additional instructions might have to be implied into data warehouse to avoid it after being deceived into affecting statistics into situation anywhere it must not exist. Query administrator involves changes to switch some contact limitations. Query administrator would essential to be alert of altogether further observations and combinations $[10,11]$.

\subsection{Record scheme}

Record plan is similarly precious since once safety events have executed; here has growth in amount of observations and tables. It is tallying safety growths extent of record and later raises difficulty of record scheme and controlling. It would also enhance difficulty to back up controlling and retrieval strategy [12].

\subsection{Testing}

Testing data warehouse has compound and extended procedure. Adding safety to data warehouse similarly moves testing period difficulty. It moves testing in following two methods:

- It would raise period mandatory for combination and system testing.

- There is extra functionality to be verified which resolve growth extent of testing group [13].

\section{RESULT AND DISCUSSION}

Development of producing a safety scheme has disintegrated into four sub-divisions. These sub-divisions deliver an integrated result for statistics security for individually classification category. A comprehensive description of the four sub-divisions follows in the above first section of the statement. The overall development has defined in the following figure 4. 


\section{International Journal of Engineering Applied Sciences and Technology, 2020 \\ Vol. 4, Issue 10, ISSN No. 2455-2143, Pages 343-347 \\ Published Online February 2020 in IJEAST (http://www.ijeast.com)}

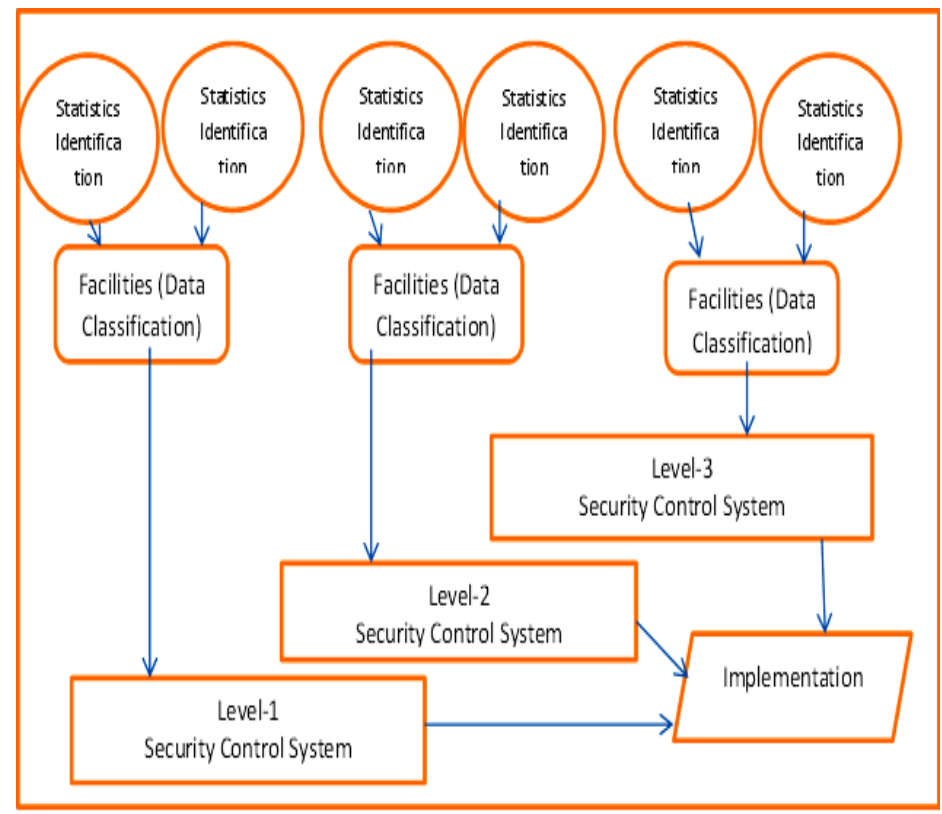

Fig4. Control and security Scheme Analysis and Implementation of data warehouse system

First, statistics information identification and next a facilities data classification that statements the operationally run into threats has allocated to each class of data. Statistics information in the security control system under facilities have termed, defined, and allocated a statistics kind according to their purpose as defined by the security control system orientation model. Then, the statistics has categorized according to its criticality to security control system actions. Finally, practical implementation direction and strategies have assumed to let the level of security control essential by the protection facilities. Data warehouse subdivision exposed in data mart analysis of each sale sub-division and marketing sub-division show in table1 and figure5.

Table1: Data warehouse subdivision exposed in data mart yearly analysis

\begin{tabular}{|r|r|r|}
\hline Yearly & Sales Data Mart & Marketing Data Mart \\
\hline 2015 & 10000 & $80 \%$ \\
\hline 2016 & 15000 & $70 \%$ \\
\hline 2017 & 21000 & $60 \%$ \\
\hline 2018 & 25000 & $50 \%$ \\
\hline 2019 & 31000 & $40 \%$ \\
\hline
\end{tabular}

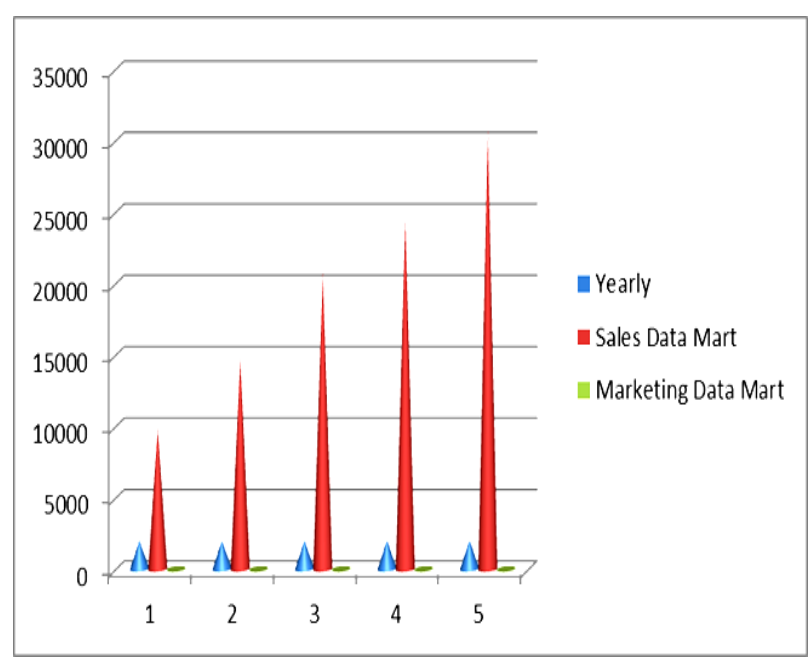

Fig5. Data warehouse subdivision exposed in data mart yearly analysis

\section{CONCLUSION AND FUTURE WORK}

The purpose of this data classification approach is to give the utility administrator, control engineers, and IT people a cohesive approach to understanding the necessary protection, prospect, and limitations of deploying security methods based on data classification in process control environments. The proposed security solution considers both operational requirements, such as performance constraints and services provided, and security requirements, such as availability, reliability, and authenticity.

\section{FUTURE WORK}

Using this control-system-specific approach, data that's more important will be better protected. This enables optimal use security resources. Data warehouse sub-division exposed sale and marketing analysis have defined in yearly system which has updated the sale and profit increase of organization.

\section{REFERENCES}

[1] Han, J. et al. (2012). "DATA MINING: Concepts and Techniques", Elsevier, pp- 327-346.

[2]Singh Dharm (2013). "Analysis of Data Mining Classification with Decision tree Technique" Global Journal of Computer Science and Technology Software \& Data Engineering Volume 13 Issue 13 Version 1.0, pp-1-7.

[3] Changala, R. et al. (2012). "Classification by decision tree induction algorithm to learn decision trees from the class labeled training tuples", International Journal of Advanced Research in Computer Science and Software Engineering, Vol. 2 Issue 4. 


\section{International Journal of Engineering Applied Sciences and Technology, 2020 \\ Vol. 4, Issue 10, ISSN No. 2455-2143, Pages 343-347 \\ Published Online February 2020 in IJEAST (http://www.ijeast.com)}

[4] Cabibbo,Luca et al. (2006.)."Tool for the Integration of Autonomous Data Marts", Proceedings of the 22nd International Conference on Data Engineering, in proceedings of IEEE ICC.

[5] Fu X., Wang L. (2003). "Data dimensionality reduction with application to simplifying RBF network structure and improving classification performance", IEEE transactions on systems, man, and cybernetics, Vol- 33, Issue no 3.

[6] Lakshmi, B.N., Raghunandhan, G.H. (2011). A conceptual overview of data mining. Proceedings of the National Conference on Innovations in Emerging Technology, 27-32.

[7] Han, E. Karypis G. (2000). "Centroid-based document classification analysis and experimental result", Proceedings of the 4th European Conference on Principles of Data Mining and Knowledge Discovery pp. 424-31.

[8] Agrawal, R. , Ram B. (2015). "A survey of uncertain data mining techniques", International Journal of Advance Research in Education, Technology and Management, 3(1):252-56, April.

[9] Ron Melton, et al., "System Protection Profile - Industrial Control Systems, National Institute of Standards \& Technology"

http://www.isd.mel.nist.gov/projects/processcontrol/SPP-

ICSv1.0.pdf

[10]Paulraj Ponniah, (2005). "Data Warehousing fundamentals", Book-Wiley.

[11] Rosenthal Arnon, Sciore Edward, (2000) "View Security as the Basis for Data Warehouse Security", Proceedings of the International Workshop on Design and Management of Data Warehouse (DMDW'2000), Sweden, June.

[12] Fernandez-Medina E., et al. (2007). "Developing secure data warehouses with a uml extension", International Journal Information systems, 3(2 pp-826-859.

[13] Han Jiawei, et al. (2004) "Data mining Concepts and Techniques", Third editions. 